\section{Sayın Editör,}

Türkiye Acil Tıp Dergisi'nin 3. sayısında yayınlanan [2010;10(3):137-140] Sayın Dr. Nail Özdemir ve arkadaşlarının "Clopidrogel'in Tetiklediği Akut Subdural Hematom" başlıklı olgu sunumunu okudum. Yazı hakkındaki görüşlerimi editör ve dergi okurları ile paylaşmak istedim.

Sunumun başlığı ve tartışma içinde verilen kaynaklar incelendiğinde, yazarların "olgudaki kanamaya clopidogrelin yol açtığını" düşündükleri anlaşılmaktadır. Tartışma içerinde, yazarların gösterdikleri kaynakların tamamına yakını clopidogrel ve aspirin alan hastalardaki "spontan kafa içi kanamalı" hastaları incelemektedir. Ancak, hastanın başvuru anında çekilmiş ilk beyin tomografisinde sağda, frontal bölgede cilt altı hematomundan, hastanın senkop sırasında bir kafa travmasına maruz kaldığı anlaşılmaktadır. Hastanın takibinde 14 saat sonra bilinci kapanmış ve akut subdural hematom gelişmiştir. "Subdural hematoma, sadece clopidogrel'in yol açması" hipotezi yerine, "antiagregan kullanan bir hastada kafa travması sonrası gecikmiş bir subdural hematomun gelişmesi" tartışılmalıydı. Bu yüzden olgunun tartışma ve sonuç bölümünün daha çok "kafa travması ile acil servise başvuran ve clopidogrel kullanan hastalara" yönelmesi gerektiğini düşünüyorum.

Antiagregan ve antikoagülan kullanan kafa travmalı hastalar üzerine yapılmış çalışmalar incelendiğinde birbirine karşıt sonuçlar çıkmaktadır: Emergency Medical Journal'da 2007 yılında yayın- lanan "Does clopidogrel increase morbidity and mortality after minor head injury" isimli makalede, 1950 ile 2007 yılları arasında kanıta dayalı olarak tüm literatür taranmış ve clopidogrelin, kafa travmalı hastalarda kafa içi kanama ile direkt ilişkisi olduğuna dair yeterli bir kanıt bulunamamıştır. ${ }^{[1]}$ Benzer şekilde Fortuna ve ark. tarafından 2008 yılında yayınlanan geriye dönük bir araştırmada, 416 hasta incelenmiş ve klopidogrel, aspirin veya varfarin kullanımının mortalite ile ilişkisinin olmadığı, mortalite konusunda tek belirleyicinin "hasta yaşı" olduğu gösterilmiştir. ${ }^{[2]}$

Bu bulgulara karşıt olarak, Brewer ve ark.'nın 2010 yılında yayınlamış olduğu "Incidence and Predictors of Intracranial Hemorrhage After Minor Head Trauma in Patients Taking Anticoagulant and Antiplatelet Medication" başlıklı çaIışmada varfarin veya clopidogrel kullanan, Glaskow Koma Skalası 15 olan, minör kafa travmalı 141 hasta değerlendirilmiştir. Bu çalışmada bilinç kaybı olan hastalarda, antikoagulan veya antiagregan kullanımının daha yüksek oranda kafa içi kanama ile ilişkili olduğu saptanmıştır. ${ }^{[3]}$ Yine Ivascu ve ark. tarafından 2008 yılında, 109 hastayı kapsayan "Predictors of mortality in trauma patients with intracranial hemorrhage on preinjury aspirin or clopidogrel" başlıklı çalışmasında, kafa içi kanama saptanan yaşlı hastalarda aspirin, klopidogrel ve aspirin + klopidogrel kullanımının yüksek mortalite ile ilişkili olduğu belirtilmiştir. ${ }^{[4]}$

Bu noktanın dışında, yazarların olgu bildirisinin sonucunda belirttiği görüşün ("klopidogrelin özellikle kafa içi kanama yönünden risk faktörü taşıyan -70 yaş üzeri, hipertansiyon mevcudiyeti, önceki serebrovasküler ataklar- ve kafa içi vaskülopati gibi patolojisi bilinen hastalarda dikkatli kullanılmalıdır") sadece bir olgu sunumundan yola çıkarak ifade edilemeyeceğini düşünüyorum. Bu tip genellemeleri yapabilmek için kontrollü, ileri yönelik çalışmalara intiyaç vardır. Bu yazıdan alınacak çıkarımın "klopidogrel kullanan kafa travmalı yaşı ı hasta popülasyonunda, gecikmiş subdural hematomlar için hekimlerin dikkatli olması ve hastayı yakından takip etmesi gerektiği" olduğunu düşünüyorum.

\section{Saygılarımla}

Dr. İsa Kilıçaslan

\section{Kaynaklar}

1. Parris R, Hassan Z. Does clopidogrel increase morbidity and mortality after minor head injury. Emerg Med J 2007;24:435-6.

2. Fortuna GR, Mueller EW, James LE et al. The impact of preinjury antiplatelet and anticoagulant pharmacotherapy on outcomes in elderly patients with hemorrhagic brain injury. Surgery. 2008;144:598-603; discussion 603-5.

3. Brewer ES, Reznikov B, Liberman RF et al. Incidence and Predictors of Intracranial Hemorrhage After Minor Head Trauma in Patients Taking Anticoagulant and Antiplatelet Medication. J Trauma. 2010 Aug 5. [Epub ahead of print]

4. Ivascu FA, Howells GA, Junn FS et al. Predictors of mortality in trauma patients with intracranial hemorrhage on preinjury aspirin or clopidogrel. J Trauma 2008;65:785-8.

Geliş tarihi (Submitted): 9.01.2011 Kabul tarihi (Accepted): 28.01.2011

İletişim (Correspondence): Dr. İsa Kılıçaslan. Birlik Mah., 439. Sok., Tunalı Hilmi Apt. No: 1/3, Çankaya 06650 Ankara, Turkey

e-posta (e-mail): isakilicaslan@hotmail.com 